\title{
Importance of reflux symptoms in functional dyspepsia
}

\author{
P K Small, M A Loudon, B Waldron, D Smith, F C Campbell
}

\begin{abstract}
The relation between symptom severity in gastro-oesophageal reflux disease (GORD) and quantitated oesophageal acid reflux is variable. Furthermore, when oesophageal acid exposure lies within the conventional normal range, the cause of the symptoms is unknown. This prospective study evaluated 24 hour ambulatory oesophageal $\mathrm{pH}$ profiles in relation to objective symptom scores in 100 dyspeptic patients who were free from ulcer and gall stones. Twenty patients had raised oesophageal acid exposure and reflux symptoms consistent with GORD, and 80 had oesophageal pH profiles within the conventional normal range. Forty four of the 80 had severe or moderate reflux symptoms and were classified as having reflux like functional dyspepsia (RFD); 36 had minimal or absent reflux symptoms, and were categorised as having non-reflux dyspepsia (NFD). While oesophageal $\mathrm{pH}$ profiles lay within the conventional normal range in both functional dyspepsia subgroups, patients with RFD had consistently greater acid exposure values as follows: mean (SEM) total oesophageal acid exposure time, RFD $16.2(2 \cdot 56)$ min $v$ NFD 9.05 (2.0) $\min (p<0.03)$; percentage of time with $\mathrm{pH}<4$, RFD $1.4(0.2) v$ NFD $0.8(0.2) \quad(p<0.03) ;$ DeMeester scores, RFD $12.8(0.5) v$ NFD $11.4(0.4)(p<0.03)$. The RFD group had a pain/reflux event correlation of $23.8(5 \cdot 3) \% \quad v \quad 8 \cdot 1$ (3.7) $\%$ for the NFD group $(\mathbf{p}<0.01)$. This study shows that patients with RFD have oesophageal acid exposure that lies below the diagnostic threshold for GORD, but exceeds that of patients with NFD. The high pain/reflux event correlation in RFD, suggests that subthreshold oesophageal acid exposure may be associated with troublesome reflux symptoms.

(Gut 1995; 36: 189-192)
\end{abstract}

Keywords: dyspepsia, oesophageal acid.

Gastro-oesophageal reflux disease (GORD) is common and may affect up to $7 \%$ of the population. ${ }^{1}$ While symptoms of heartburn and regurgitation are suggestive of acid reflux, ${ }^{2}$ a firmer diagnosis may be established by objective tests. Oesophagoscopy, with or without biopsy, may reveal oesophagitis, which is highly specific for acid reflux, but of poor sensitivity. ${ }^{3}$ Prolonged oesophageal ambulatory $\mathrm{pH}$ monitoring is regarded as a 'gold standard' for an objective diagnosis of reflux and quantification of oesophageal acid exposure. $^{4-7}$

However, the problem remains of patients with reflux symptoms who have negative results for both endoscopy and $\mathrm{pH}$ monitoring. The term 'reflux like' functional (or non-ulcer) dyspepsia has been applied to this group, with the inference of a relation to acid reflux but conclusive data are lacking. ${ }^{8}$ The study has investigated reflux symptoms in relation to objective measures of oesophageal acid reflux, by 24 hour ambulatory $\mathrm{pH}$ monitoring, in a large cohort of dyspeptic patients who were free from other organic gastrointestinal disease. It aimed to assess the sensitivity of the conventional diagnostic threshold of oesophageal acid exposure as assessed by ambulatory $\mathrm{pH}$ monitoring.

\section{Patients and methods}

STUDY POPULATION

One hundred and ten dyspeptic patients were entered into a prospective pathophysiological study of functional dyspepsia. Peptic ulcer and gall stones were excluded by gastroscopy and abdominal ultrasound examination, as previously described. ${ }^{9}$ All patients had had persistent upper abdominal or retrosternal dyspeptic symptoms, or both, for at least two years before the study. Seven patients were found to have gall stones, peptic ulcer, or malignancy and were excluded. A further three failed to complete ambulatory oesophageal $\mathrm{pH}$ studies, leaving 100 evaluable patients. Objective symptom assessments and 24 hour ambulatory oesophageal $\mathrm{pH}$ studies were carried out on all 100 patients.

\section{SYMPTOM ASSESSMENT}

The severity of dyspeptic symptoms including heartburn, regurgitation, early satiety, bloating, epigastric pain, anorexia, nausea, and vomiting were assessed using visual analogue

TABLE I Age and sex distribution of patient groups. (Values given are mean (SEM))

\begin{tabular}{lllll}
\hline & GORD & RFD & NFD & $p$ Value \\
\hline Age (y) & $46(4)$ & $41(2)$ & $42(2)$ & NS $^{\star}$ \\
Sex $(M, F)$ & 12,8 & 17,27 & 13,23 & NS $\dagger$ \\
\hline
\end{tabular}

${ }^{\star}$ Mann-Whitney U test. $+\chi^{2}$ test. GORD = gastro-oesophageal reflux disease; $R F D=$ reflux-like dyspepsia; $\mathrm{NFD}=$ non-functional dyspepsia.
Correspondence to: Mr F C Campbell, Department of Surger Medical School, Dundee DD1 9 SY.

Accepted for publication 27 May 1994 
TABLE II Comparison of $p H$ measurements between patients with gastro-oesophageal reflux (GORD) using current criteria and patients with reflux like dyspepsia. (Values given are mean (SEM))

\begin{tabular}{llll}
\hline & & & \\
& GORD & RFD & Value \\
\hline Total acid exposure (min) & $130.08(19 \cdot 5)$ & $16.2(2 \cdot 6)$ & $<0.001$ \\
DeMeester score & $31.3(2.9)$ & $12.8(0.5)$ & $<0.001$ \\
Pain/reflux correlation & $52(9.7)$ & $24(5 \cdot 3)$ & $<0.03$ \\
$\%$ time pH $<4$ & $10.8(1.5)$ & $1 \cdot 4(0.2)$ & $<0.001$ \\
\hline
\end{tabular}

${ }^{\star}$ Mann-Whitney U test. RFD=reflux like dyspepsia.

scales. ${ }^{10}$ Patients were asked to score the most severe episode of each symptom (if present) during the previous two weeks.

\section{AMBULATORY PH STUDIES}

Ambulatory $\mathrm{pH}$ monitoring was carried out using a pH sensitive electrode suspended $5 \mathrm{~cm}$ above the manometrically determined high pressure zone. Data were recorded by a portable microprocessor receiving unit (Aspen Medical Ltd, Ross-shire, Scotland). Analysis of the data was carried out by a microcomputer running dedicated software, which gave the mean time of oesophageal $\mathrm{pH}<4$, and the mean number and duration of reflux events in both the erect and supine position. The onset of a reflux event was defined as a drop in oesophageal $\mathrm{pH}$ to below 4 , and its termination when oesophageal $\mathrm{pH}$ rose to 4 or above. Total acid exposure was expressed as a percentage of data below each $\mathrm{pH}$ unit from 3 to 9 during the study period. A diagnosis of GORD was made if any one of these parameters exceeded the upper limit of the conventional normal range, defined as $>3 \mathrm{SD}$, or any two parameters $>2$ SD above the mean of a group of 22 normal controls, as described elsewhere. ${ }^{1112}$ A DeMeester type score, based on six parameters of acid reflux, was calculated according to conventional guidelines. Values above 22 represent abnormal acid reflux. ${ }^{13}$

An electronic event marker, activated by the patient, placed a visual signal on the $\mathrm{pH}$ tracing. Both this method and a diary system were used to record subject pain. Any relation between pain events and reflux episodes was sought.

\section{PATIENT CATEGORIES}

Patients with abnormal $\mathrm{pH}$ profiles as described above were categorised as having GORD. Reflux type symptoms (heartburn and acid reflux) of patients whose oesophageal $\mathrm{pH}$ profiles lay within the conventional normal

TABLE III Comparison of $p H$ measurements between patients with reflux like dyspepsia (RFD) and those without troublesome reflux symptoms (NFD). (Values given are mean (SEM))

\begin{tabular}{llcl}
\hline & $R F D$ & NFD & $\stackrel{p}{\text { Value }^{\star}}$ \\
\hline Total acid exposure (min) & $16 \cdot 2(2 \cdot 6)$ & $9 \cdot 05(2 \cdot 0)$ & $<0 \cdot 03$ \\
DeMeester score & $12 \cdot 8(0 \cdot 5)$ & $11 \cdot 8(0 \cdot 4)$ & $<0 \cdot 03$ \\
Pain/reflux correlation & $24(5 \cdot 3)$ & $8 \cdot 1(3 \cdot 7)$ & $<0.01$ \\
$\%$ time pH $<4$ & $1 \cdot 4(0 \cdot 2)$ & $0 \cdot 8(0 \cdot 2)$ & $<0.03$ \\
\hline *Mann-Whitney U test. & & & \\
\hline
\end{tabular}

range were then graded using visual analogue scales of $0-10$. Patients were assigned to one of two groups on the basis of the severity of these symptoms (reflux like functional dyspepsia (RFD) indicated moderate/severe symptoms, and non-reflux functional dyspepsia (NFD) mild/absent symptoms) according to the criteria below:

\section{Severity score}

Severe: heartburn $>7$;

Moderate: heartburn $>3$ or regurgitation $>5$;

Mild: heartburn $\leqslant 3$ or regurgitation $\leqslant 5$;

Absent: heartburn $=0$ and regurgitation $=0$.

\section{ETHICAL CONSIDERATIONS}

Ethical approval was granted by Tayside Committee on Medical Ethics. All patients gave fully informed consent to participation in the study.

\section{DATA ANALYSIS}

Descriptive statistics were the mean (SEM). Evaluation of differences between groups was by the Mann-Whitney $U$ test. The $\chi^{2}$ statistic was used to compare groups for sex distribution.

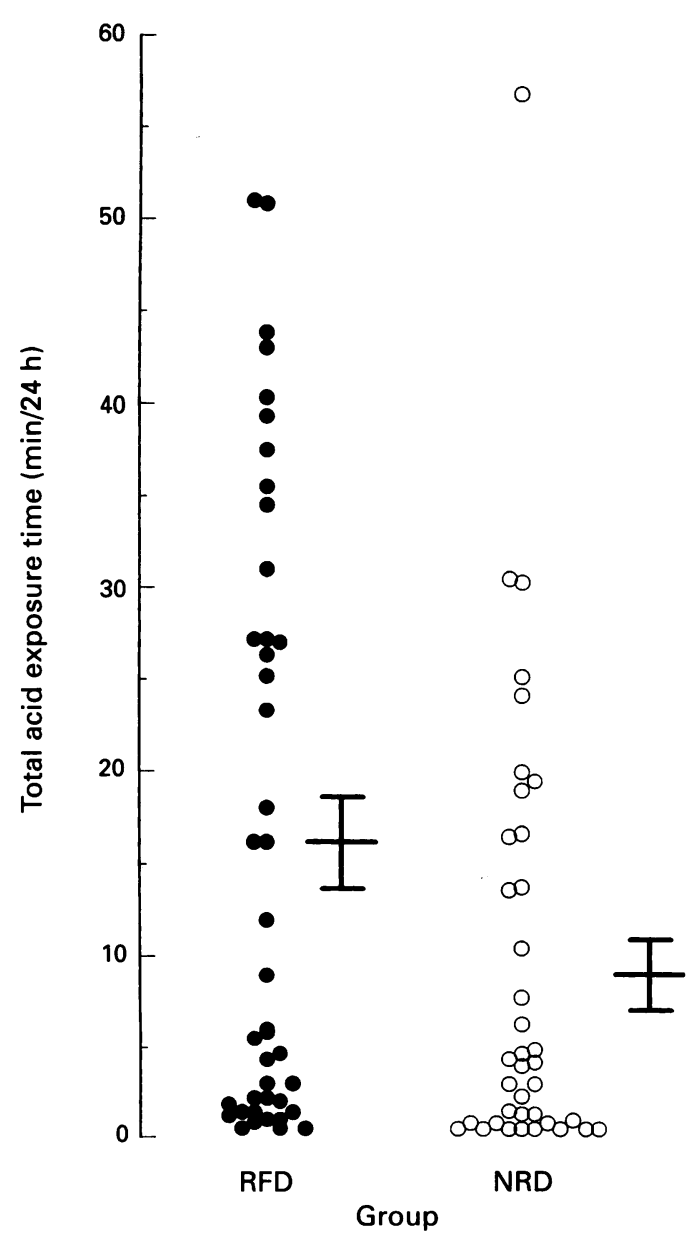

Figure 1: Comparison of total acid exposure ( $\mathrm{min} / 24 \mathrm{~h})$ in reflux like dyspepsia (RFD) and non-reflux functional dyspepsia (NFD) groups. (Mean (SEM) RFD 16.2 (2.6) and NFD $9.05(2 \cdot 0) ; p<0 \cdot 03$, Mann-Whitney U test.) 


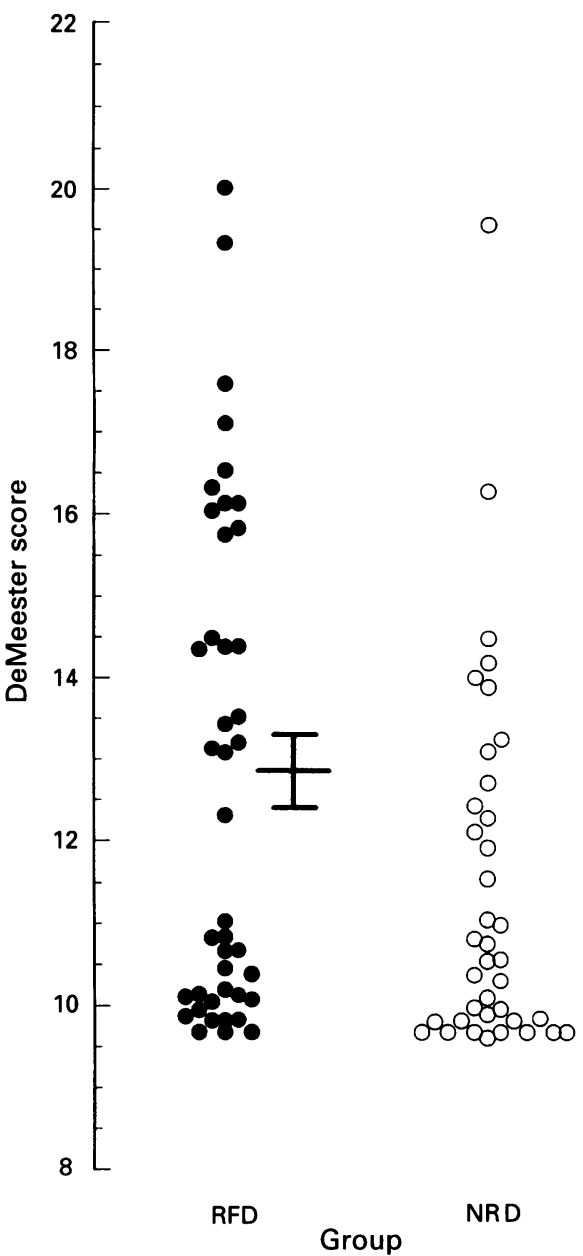

Figure 2: Comparison of DeMeester scores for reflux like dyspepsia (RFD) and non-reflux functional dyspepsia (NFD) groups. (Mean (SEM) RFD 12.8 $(0.5)$ and NFD $11.4(0.4) ; p<0.03$, Mann-Whitney U test.)

\section{Results}

On the basis of ambulatory oesophageal $\mathrm{pH}$ monitoring and symptom assessment, 20 patients were classified as suffering from GORD, 44 as having RFD and 36 as having NFD. Age and sex distributions were comparable in the three groups (Table I). Reflux symptom scores were similar for GORD and RFD (mean (SEM) heartburn, GORD $4.3(1.04) v$ RFD $4.76(0.46), \mathrm{p}=\mathrm{NS}$ (MannWhitney $U$ test); regurgitation GORD $2 \cdot 46$ $(1.08) v \operatorname{RFD} 3.79(0 \cdot 5), \mathrm{p}=\mathrm{NS})$. Reflux symptom scores were greater in RFD than NFD (heartburn $4.76(0.46) v 0.18(0.09)$, $\mathrm{p}<0.001$ and regurgitation $3.79(0.5) v 0.72$ $(0 \cdot 19), \mathrm{p}<0 \cdot 001$, respectively.

All pH parameters of acid reflux were significantly greater in GORD patients than in the RFD group (Table II). Although values for total acid exposure, DeMeester scoring, pain/reflux correlation, and percentage time $\mathrm{pH}<4$ lay within the conventional normal range in both functional dyspepsia groups, all parameters were significantly greater in RFD than NFD (Table III, Figs 1-3). A proportion of patients in the RFD group who had a pain/reflux event correlation of $50 \%$ or more, also had the highest oesophageal acid exposure within the group (Table IV).

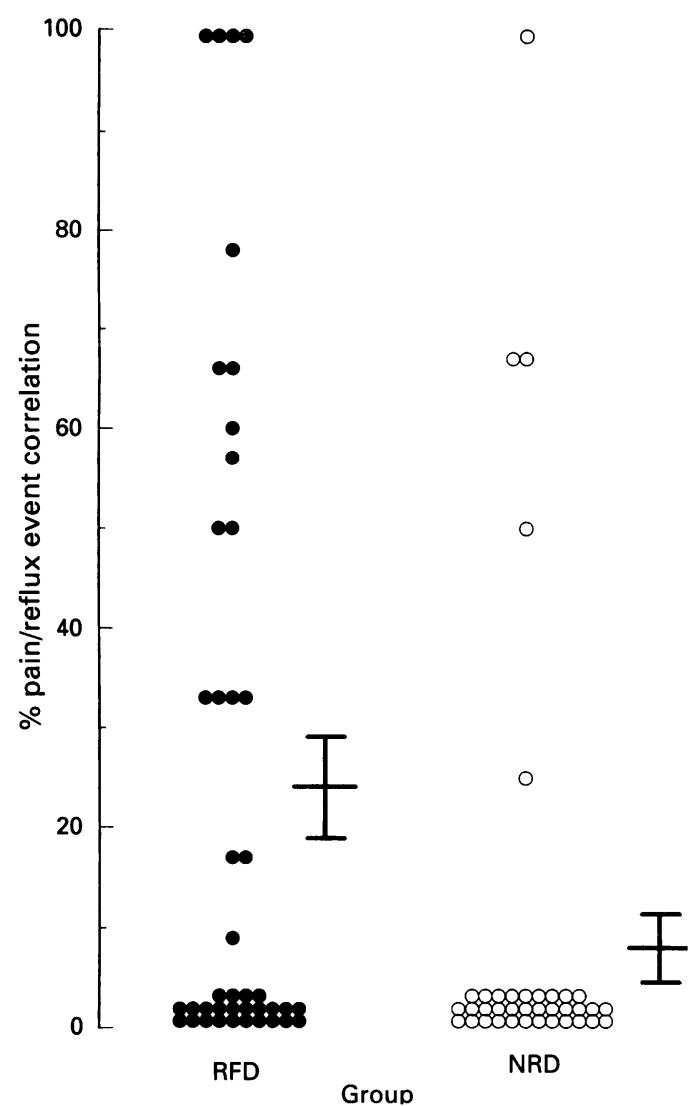

Figure 3: Comparison of \% pain/reflux event correlation in reflux like dyspepsia (RFD) and non-reflux functional dyspepsia (NFD) groups. (Mean (SEM) RFD $24(5 \cdot 3)$ and NFD $8 \cdot 1(3 \cdot 7) ; p<0 \cdot 001$, Mann-Whitney $U$ test.)

\section{Discussion}

Conventional acid suppression treatment improves reflux symptoms, and may potentially impede the development of some complications. Accurate diagnosis of acid reflux, however, can be difficult, and that based on reflux symptoms alone is inaccurate. ${ }^{2}$ Endoscopic diagnosis depends on macroscopic damage, which is evident in only $50-60 \%$ of symptomatic patients. ${ }^{1415}$ Twenty four hour ambulatory oesophageal $\mathrm{pH}$ monitoring provides objective data on quantitative oesophageal acid exposure and is considered a diagnostic 'gold standard' for GORD. ${ }^{3-7} \mathrm{~A}$ positive diagnosis is made when parameters of oesophageal acid reflux, including the total acid exposure time or time when oesophageal $\mathrm{pH}$ is less than 4 , exceeds the mean of a normal control group by 2 or 3 SD. ${ }^{12}$

In this study, 20 of 64 patients with troublesome reflux symptoms were diagnosed as having GORD by 24 hour ambulatory $\mathrm{pH}$

TABLE IV Comparison of $p H$ measurements between patients with reflux like dyspepsia who have a pain/reflux correlation of more than or less than $50 \%$. (Values given are mean (SEM))

\begin{tabular}{llll}
\hline & $\begin{array}{l}>50 \% \\
\text { correlation }\end{array}$ & $\begin{array}{l}<50 \% \\
\text { correlation }\end{array}$ & $\begin{array}{l}\text { Value } \\
\text { Val }^{\star}\end{array}$ \\
\hline No of patients & 10 & 24 & \\
Total acid exposure (min) & $25 \cdot 3(5 \cdot 3)$ & $12 \cdot 9(2 \cdot 7)$ & $<0.02$ \\
DeMeester score & $14 \cdot 4(0.9)$ & $12 \cdot 2(0 \cdot 5)$ & $<0 \cdot 02$ \\
Pain/reflux correlation & $75 \cdot 2(6 \cdot 4)$ & $5 \cdot 6(2 \cdot 08)$ & $<0 \cdot 001$ \\
\% time pH <4 & $2 \cdot 1(0 \cdot 4)$ & $1 \cdot 2(0 \cdot 2)$ & $<0.04$ \\
\hline
\end{tabular}

^Mann-Whitney U test. 
monitoring. The remaining 44 patients, categorised as having reflux like functional dyspepsia (RFD), had parameters of oesophageal acid exposure below the diagnostic threshold for GORD but, none the less, these were significantly higher than those of dyspeptic patients without reflux symptoms (NFD). As a whole, RFD patients had a higher pain/reflux event correlation than NFD patients, which suggests a relation of subthreshold oesophageal acid exposure to symptoms. A pain/reflux event correlation of $50 \%$ or greater in RFD patients was associated with significantly greater parameters of oesophageal acid exposure compared with the remainder of the group. Other investigators have suggested that a high pain/reflux event correlation be given greater weight in diagnosis, ${ }^{1617}$ yet few of the current diagnostic criteria for acid reflux by $\mathrm{pH}$ monitoring take any account of the temporal relation of symptoms to reflux episodes.

The equal symptom severity scoring between patients with GORD and RFD is of interest. It is possible that greater oesophageal sensitivity to acid between subjects may be an important factor, as has been suggested previously. ${ }^{18}$

In conclusion, our data suggest that the conventional criteria used by 24 hour ambulatory $\mathrm{pH}$ monitoring to diagnose symptomatic oesophageal acid reflux, may be insufficiently sensitive. This study shows that subthreshold oesophageal acid exposure, which may represent infrequent or brief episodes of acid reflux, could contribute to troublesome reflux symptoms.

1 Nebel OT, Fornes MF, Castell DO. Symptomatic gastrooesophageal reflux: incidence and precipitating factors. oesophageal reflux: incidence and precipitating factors. 2 Klauser AG, Schindlbeck NE, Muller-Lissner SA.
Symptoms in gastro-oesophageal reflux disease. Lancet 1990; 335: 205-8.

3 Klauser AG, Heinrich C, Schindlbeck NE, Muller-Lissner $\mathrm{SA}$. Is long term esophageal $\mathrm{pH}$ monitoring of clinical value? Am $\mathcal{f}$ Gastroenterol 1989; 84: 362-5.

4 Wiener GJ, Morgan TM, Copper JB, Wu WC, Castell DO, Sinclair JW, et al. Ambulatory 24-hour esophageal pH monitoring, reproducibility and variability of $\mathrm{pH}$ parameters. Dig Dis Sci 1988; 33 (9): 1127-33.

5 Mattioli S, Pilott V, Spangaro M, Grigioni WF, Zannoli R, Felice V, et al. Reliability of 24-hour home oesophageal $\mathrm{pH}$ monitoring in diagnosis of gastro-oesophageal reflux. Dig Dis Sci 1989; 34: 71-8.

6 Johnsson F, Joelsson B, Isberg P-E. Ambulatory 24 hour intra-oesophageal $\mathrm{pH}$-monitoring in the diagnosis of gastro-oesophageal reflux disease. Gut 1987; 28: $1145-50$.

7 Jamieson JR, Stein HJ, DeMeester TR, Bonavina L, Schwizer W, Hinder AR, et al. Ambulatory 2-H Schwizer W, Hinder AR, et al. Ambulatory 2-H
oesophageal pH monitoring: normal values, optimal thresholds, specificity sensitivity and reproducibility. $\mathrm{Am} \mathcal{F}$ Gastroenterol 1992; 87: 1102-11.

8 Colin-Jones DG. Management of dyspepsia: report of a working party. Lancet 1988; i: 576-9.

9 Waldron B, Cullen PT, Kumar R, Smith D, Jankowski J, Hopwood D, et al. Evidence for hypomotility in non-ulcer dyspepsia: a prospective multifactorial study. Gut 1991; 32: $246-51$.

10 Bates S, Sjoden P-O. Registration of pain in a psychological perspective. Scand $\mathcal{f}$ Gastroenterol 1985; 20 (suppl 109); perspecti

11 Vitale GC, Sadek S, Tulley FM, Rimmer AR, Hunter BE, Phelan J, Cuschieri A. Computerised 24-hour oesophageal $\mathrm{pH}$ monitoring: a new ambulatory technique using radiotelemetry. F Lab Clin Med 1985; 105: 686-93.

12 Vitale GC, Cheadle WG, Sadek S, Michel ME, Cuschieri A. Computerised 24-hour ambulatory oesophageal monitoring and esophagogastroduodenoscopy in the reflux patient. Ann Surg 1984; 200: 724-8.

13 Johnson LF, DeMeester TR. Development of the 24-hour intra-oesophageal $\mathrm{pH}$ monitoring composite scoring system. F Clin Gastroenterol 1986; suppl 1: 52-8.

14 Rokkas T, Sladen GE. Ambulatory esophageal pH recording in gastroesophageal reflux: Relevance to the developing in gastroesophageal reflux: Relevance to the develop-
ment of esophagitis. Am $\mathcal{F}$ Gastroenterol 1988; 83: 629-32.

15 Shay SS, Abreu SH, Tsuchida A. Scintigraphy in gastroesophageal reflux disease: A comparison to endoscopy, LESp, and $24-\mathrm{H} \mathrm{pH}$ score, as well as to simultaneous $\mathrm{pH}$ monitoring. Am $\mathcal{F}$ Gastroenterol 1992; 87: 1094-101.

16 Vantrappen G, Janssens J, Ghillebert G. The irritable oesophagus - a frequent cause of angina-like pain. Lancet 1987; i: 1232-4.

17 Howard PJ, Pryde A, Heading RC. Relationship between gastro-oesophageal reflux and symptoms in patients referred for ambulatory $\mathrm{pH}$ monitoring. Fournal of Gastrointestinal Motility 1990; 4: 231-9.

18 Wiener GJ, Richter JE, Copper PA, Wu MC, Castell DO. The symptom index: a clinically important parameter of ambulatory 24-hour oesophageal pH monitoring. Am $\mathcal{F}$ Gastroenterol 1988; 83: 358-61. 